\title{
Dietary counselling and food fortification in stable COPD: a randomised trial
}

\author{
C E Weekes, ${ }^{1}$ P W Emery, ${ }^{2}$ M Elia ${ }^{3}$
}

- Additional Methods and Results details are published online only at http://thorax.bmj. com/content/vol64/issue4

${ }^{1}$ Department of Nutrition and Dietetics, Guy's \& St Thomas' NHS Foundation Trust, St Thomas' Hospital, London, UK; ${ }^{2}$ Nutritional Sciences Division, King's College London, London, UK: ${ }^{3}$ Institute of Human Nutrition, University of Southampton, Southampton, UK

Correspondence to:

Dr C E Weekes, Department of Nutrition and Dietetics, Guy's \& St Thomas' NHS Foundation

Trust, St Thomas' Hospital, London SE1 7EH, UK; elizabeth.weekes@gstt.nhs.uk

Received 12 February 2008 Accepted 20 November 2008

Published Online First

14 December 2008

\section{ABSTRACT}

Background: Malnutrition in chronic obstructive pulmonary disease (COPD) is associated with a poor prognosis, yet evidence to support the role of dietary counselling and food fortification is lacking. A study was undertaken to assess the impact of dietary counselling and food fortification on outcome in outpatients with COPD who are at risk of malnutrition.

Methods: A randomised controlled unblinded trial was performed in 59 outpatients with COPD (6 months intervention and 6 months follow-up). The intervention group received dietary counselling and advice on food fortification and the controls received a dietary advice leaflet. Outcome measures were nutritional status, respiratory and skeletal muscle strength, respiratory function, perceived dyspnoea, activities of daily living (ADL) and quality of life.

Results: The intervention group consumed more energy (difference $194 \mathrm{kcal} /$ day; $\mathrm{p}=0.02$ ) and protein (difference $11.8 \mathrm{~g} / \mathrm{day} ; \mathrm{p}<0.001)$ than controls. The intervention group gained weight during the intervention period and maintained weight during follow-up; the controls lost weight throughout the study. Significant differences were observed between the groups in St George's Respiratory Questionnaire total score (difference 10.1; $p=0.02$ ), Short Form-36 health change score (difference 19.2; $p=0.029$ ) and Medical Research Council dyspnoea score (difference 1.0; $p=0.03$ ); the difference in ADL score approached statistical significance (difference 1.5; $p=0.06$ ). No differences were observed between groups in respiratory function or skeletal and respiratory muscle strength. Improvements in some variables persisted for 6 months beyond the intervention period.

Conclusion: Dietary counselling and food fortification resulted in weight gain and improvements in outcome in nutritionally at-risk outpatients with COPD, both during and beyond the intervention period.

In patients with chronic obstructive pulmonary disease (COPD), weight loss and being underweight are associated with a poor prognosis and increased mortality, independent of disease severity. ${ }^{1}$ Recent reviews of nutritional intervention in COPD suggest that the effects on weight change, body composition and functional measures are minimal, ${ }^{2}{ }^{3}$ in part due to the small numbers of subjects and short-term interventions. Both reviews concluded that larger randomised controlled trials are required.

In the management of malnutrition, the main aims of nutritional intervention are to maximise nutrient intake and-through minimising weight loss and/or promoting weight gain-to improve clinical and functional outcomes. To achieve these goals, dieticians may use one or any combination of the following strategies: dietary counselling to increase the frequency and/or alter the types of food and fluid consumed; food fortification to increase nutrient density of food and/or drink; provision of prescribable oral nutritional supplements (ONS). Evidence suggests that ONS are invaluable to some patients when used appropriately $^{3}$ yet, while dieticians are uniquely trained to provide dietary counselling and advice on food fortification, surprisingly little evidence exists to support these strategies. ${ }^{4}$

ONS are used routinely both in hospital and the community, yet alone they may be insufficient or inappropriate for some patients. Reported compliance rates are as low as 50\%, especially in elderly subjects, ${ }^{5}{ }^{6}$ and may be affected by taste fatigue, gastrointestinal symptoms, ${ }^{8}$ individual preferences and lifestyle. ${ }^{9}$ For some patients, dietary counselling and advice on food fortification may have advantages over ONS by offering greater variety and flexibility. Furthermore, intervention may result in changes in dietary habits that persist beyond the intervention period and thus result in maintenance of any weight gain and/or clinical and functional benefits achieved.

The aim of this study was to assess the specific impact of dietary counselling and food fortification on patient-centred outcomes in outpatients with COPD identified as being at risk of malnutrition.

\section{METHODS}

\section{Recruitment and randomisation}

Subjects were recruited in the chest clinic at St Thomas', Guy's and Lewisham Hospitals from August 2001 to May 2003. All patients with a clinical diagnosis of COPD and identified as at risk of malnutrition (score 3-5) using a validated nutrition screening too ${ }^{10}$ (see online supplement 1) were invited to participate in the study if aged $\geqslant 18$ years and able to give informed consent. Those with conditions likely to compromise nutritional status further were excluded (eg, unstable diabetes mellitus, current disseminated malignancy, congestive cardiac failure and untreated thyroid disease). Informed written consent was obtained and randomisation occurred in a standard way using sealed opaque envelopes containing randomised codes.

\section{Intervention}

Intervention lasted for the first 6 months of the study, the following 6 months being used to measure the effects of cessation. All subjects received a leaflet providing advice on nourishing snacks and drinks and encouraging food fortification. ${ }^{11}$ Controls were handed the leaflet during the 
474 patients screened in chest clinics at St Thomas', Guy's and Lewisham Hospitals

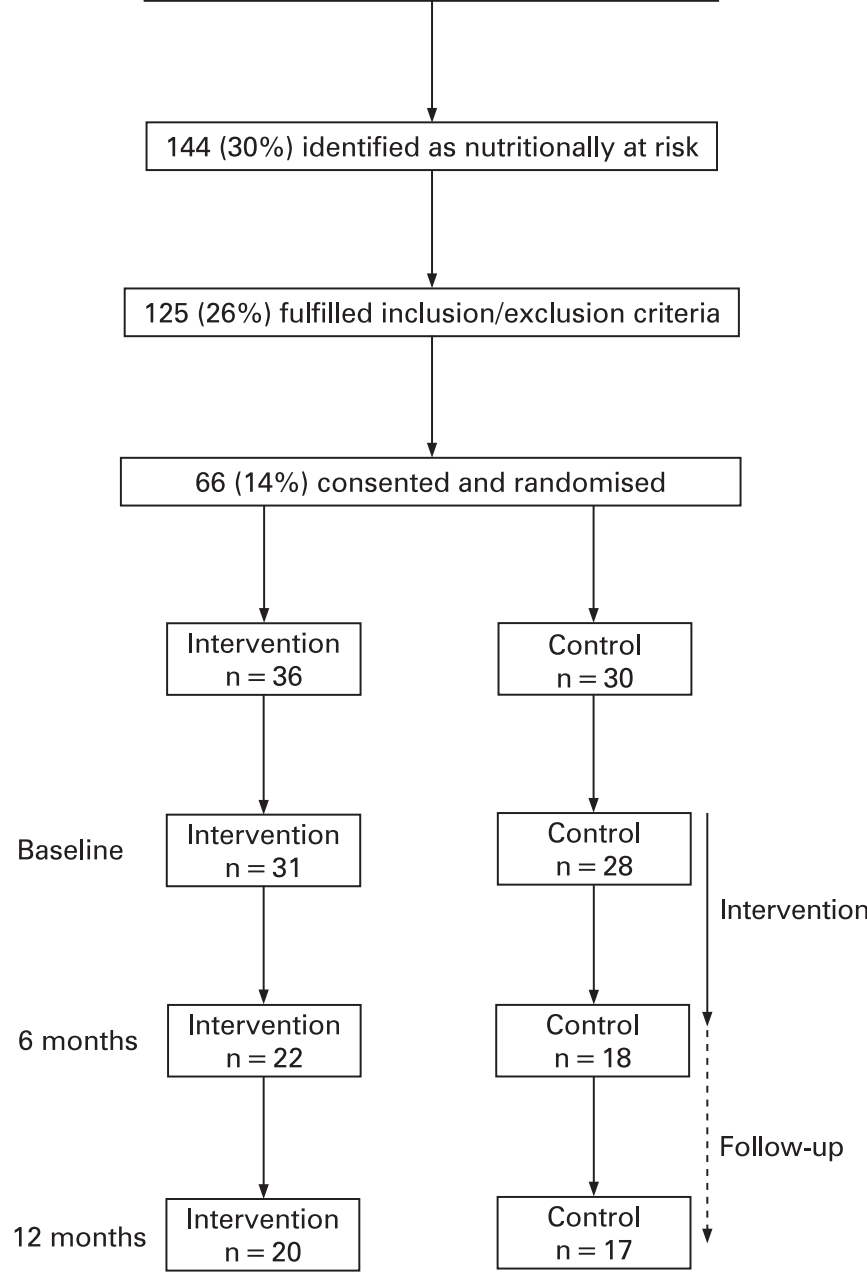

Figure 1 Trial profile.

baseline assessment but its contents were never discussed. Intervention subjects were offered a package of treatment incorporating dietary counselling by an experienced dietician (CEW) and a supply of milk powder (MP) for use in food fortification. The aim was to increase energy intake by up to $600 \mathrm{kcal} /$ day while ensuring an adequate balance of macronutrients and micronutrients (see online supplement).

\section{Outcome measures}

All assessments were conducted by the investigator (CEW) during seven home visits (baseline and months 1, 3, 6, 7, 9 and 12). Dietary intake was assessed at baseline using the diet history method and prior to all subsequent assessments using 5day dietary diaries. ${ }^{12}$ The amount of MP consumed was recorded during each assessment. Dietary intake data were analysed using Microdiet Version 1.1 (University of Salford, UK). Weight was measured without shoes in light clothing using portable scales (Soehnle, Germany). Height was measured without shoes using a wall-fixed stadiometer (Holtain, Crymych, UK). To assess changes in muscle mass, mid arm circumference (MAC) and triceps skinfold thickness (TSF) were measured and mid arm muscle circumference (MAMC) was calculated. To assess changes in fat mass, skinfold thickness was measured at four sites (biceps, triceps, subscapular and suprailiac) using Harpenden skinfold calipers (Holtain) according to standard methodology. ${ }^{13}$ The St George's Respiratory Questionnaire ${ }^{14}$ provided an assessment of respiratory health status and a generic tool, the SF-36 $6^{15}$, provided an indication of health change. Dyspnoea was assessed using the Medical Research Council (MRC) dyspnoea scale, ${ }^{16}$ a 5 -point scale where a score of 1 indicates physical activity is not limited by dyspnoea and a score of 5 indicates the patient is too dyspnoeic to leave the house. Activities of daily living (ADL) were assessed using the amended Townsend score ${ }^{17}$ which consists of 11 questions. Scores range from 0 to 22 , higher scores indicating more difficulty performing daily activities. Skeletal muscle strength was assessed on the non-dominant $\operatorname{arm}^{18}$ using a hand-grip dynamometer (Takei, Japan). Respiratory and diaphragmatic muscle strength were assessed using maximal sniff and mouth pressure measurements according to a standard protocol ${ }^{19}$ using a Morgan Pmax monitor (P K Morgan, Rainham, Kent, UK).

\section{Sample size calculation and statistical analysis}

In malnourished patients, weight gain in excess of $2.0 \mathrm{~kg}$ is associated with improved functional and clinical outcomes. ${ }^{3}$ Mean (SD) weight loss over the previous year in 198 weightlosing and thin patients with COPD seen in chest clinics at Guy's and St Thomas' Hospitals was 5.4 (3.7) kg (ie, 10 (8.6)\%). A reduction in weight loss of $3.0 \mathrm{~kg}$ would be a $55 \%$ improvement ( 0.8 of standard deviation). To detect such a difference at the $5 \%$ level with $80 \%$ power would require 26 patients in each group.

All patients who completed at least two assessments (baseline and one other) were included in an intention-to-treat analysis to provide an unbiased assessment of the treatment effect. For continuous data, the final measurement for each patient (when they withdrew, died or completed the study) was recorded and, for ordinal data, the median score was calculated for each patient from baseline until they withdrew, died or completed the study. Further analysis was conducted on all patients who completed the study to analyse changes during the intervention and post-intervention periods separately. For continuous data, one-way analysis of covariance (ANCOVA) was conducted to compare groups, controlling for baseline measurements. For non-parametric data, rank ANCOVA tests were conducted to compare groups, controlling for baseline measurements. ${ }^{20}$ All tests were two-tailed and $\mathrm{p}<0.05$ was considered statistically significant. Data were analysed on completion of the study using SPSS Version 11.5 (SPSS, Chicago, Illinois, USA). All results are reported after controlling for baseline measurements unless otherwise stated.

\section{RESULTS}

Sixty-six patients were recruited; 59 (89\%) completed the baseline assessment and 37 (56\%) completed the study (fig 1). The main reason patients failed to complete the study was deterioration in their clinical condition (see online supplement).

At baseline, no significant differences were observed between patients who completed the study $(n=37)$ and those who did not $(\mathrm{n}=22$, table 1$)$. The intervention and control groups were comparable at baseline (table 2). No subjects attended a pulmonary rehabilitation programme while participating in the study.

Fifty patients completed at least one dietary diary. The intervention group consumed significantly more energy and protein than the control group (table 3). In those who completed the study, the intervention group consumed significantly more energy $(p=0.02)$ and protein $(p<0.001)$ than 
Table 1 Baseline data comparing patients who completed the study with those who did not $(n=59)$

\begin{tabular}{|c|c|c|c|}
\hline & $\begin{array}{l}\text { Completed } \\
(\mathrm{n}=37)\end{array}$ & $\begin{array}{l}\text { Withdrew or } \\
\text { died } \\
(\mathrm{n}=22)\end{array}$ & p Value* \\
\hline \multicolumn{4}{|l|}{ Demographic data } \\
\hline Gender (M:F) & 18:19 & $12: 10$ & - \\
\hline Age (years) & $69.0(47-85)$ & $69.1(46-89)$ & 0.97 \\
\hline Weight $(\mathrm{kg})$ & $53.9(8.2)$ & $54.4(7.4)$ & 0.82 \\
\hline BMI $\left(\mathrm{kg} / \mathrm{m}^{2}\right)$ & $19.9(1.6)$ & $19.5(1.6)$ & 0.38 \\
\hline $\begin{array}{l}\text { Unintentional change from usual } \\
\text { weight }(\mathrm{kg})\end{array}$ & $-8.7(6.0)$ & $-8.6(5.6)$ & 0.93 \\
\hline$\%$ fat mass & $23.3(6.2) \dagger$ & $21.5(7.7)$ & 0.35 \\
\hline \multicolumn{4}{|c|}{ Smoking status and respiratory function } \\
\hline Ex-smokers & $20(54 \%)$ & $12(55 \%)$ & \\
\hline Smokers & $14(38 \%)$ & $10(45 \%)$ & 0.37 \\
\hline Non-smokers & $3(8 \%)$ & $0(0 \%)$ & \\
\hline $\mathrm{FEV}_{1}(\%$ predicted $)$ & $31.9(12.5)$ & $31.7(14.4)$ & 0.95 \\
\hline $\mathrm{FEV}_{1} / \mathrm{FVC}$ & $0.44(0.14)$ & $0.44(0.13)$ & 0.91 \\
\hline MRC dyspnoea score & $3(1-5)$ & $4(1-5)$ & 0.16 \\
\hline \multicolumn{4}{|l|}{ Nutrient intake (diet history method) } \\
\hline Energy (kcal/day) & $2015(406)$ & $1850(360)$ & 0.11 \\
\hline Protein (g/day) & $68.3(11.9)$ & $65.9(11.1)$ & 0.44 \\
\hline \multicolumn{4}{|l|}{ Quality of life and functional status } \\
\hline SGRO Total Score & $57.1(3.2)$ & $60.8(3.8)$ & 0.68 \\
\hline ADL score & $12(7-18)$ & $12(8-18)$ & 0.93 \\
\hline
\end{tabular}

Values are mean (range) for age, mean (SD) for weight, $\mathrm{BMI}$, unintentional weight change, \% fat mass, $\mathrm{FEV}_{1}$ (\% predicted), $\mathrm{FEV} / \mathrm{FVC}$, nutrient intake, SGRO Total score and $\mathrm{ADL}$ score and number (\%) patients for smoking status.

${ }^{*} \mathrm{p}$ values for unpaired $t$ tests for age, weight, body mass index, $\mathrm{FEV}_{1}, \mathrm{FEV}_{1} / \mathrm{FVC}$ nutrient intake and SGRO total score, $\chi^{2}$ test for smoking status and Mann-Whitney test for MRC dyspnoea and ADL scores.

$\dagger \mathrm{n}=36$ as one patient did not consent to measurement.

$A D L$, Activities of Daily Living; BMI, body mass index; $F_{E V}$, forced expiratory volume in $1 \mathrm{~s}$; FVC, forced vital capacity; SGRQ, MRC, Medical Research Council; St George's Respiratory Questionnaire.

the control group during the intervention period, although no differences were observed between the groups during follow-up (fig 2). In the intervention group, four subjects failed to comply with any advice. Of the 24 (77\%) who used MP for more than 14 days, the mean use was $26.8 \mathrm{~g} \mathrm{MP} /$ day (130 kcal/day; $4.8 \mathrm{~g}$ protein/day). None of the control group used MP during the study.

A significant difference in final body weight was observed between the intervention and control groups (table 3). In those who completed the study, intervention patients gained weight during the intervention period and maintained weight during follow-up whereas control patients lost weight throughout the study (fig 3).

Intervention patients gained fat mass and maintained muscle mass whereas control patients lost both fat and muscle mass. The observed difference between the groups in the sum of four skinfold thickness measurements was statistically significant in both the intention-to-treat analysis (table 3 ) and in those who completed the study ( 6 months: difference $6.6 \mathrm{~mm}, \mathrm{p}=0.02$; 12 months: difference $9.7 \mathrm{~mm}, p=0.01)$. The difference observed in MAMC was not statistically significant when analysed on an intention-to-treat basis. In those who completed the study, however, a significant difference in MAMC was observed between the groups at 12 months (difference $0.9 \mathrm{~cm}$, $p=0.04$ ) but not at 6 months (difference $0.5 \mathrm{~cm}, p=0.15$ ).

Forty-one patients completed the SGRQ and the SF-36 on at least two occasions (baseline plus one other). In the intentionto-treat analysis the intervention group reported significantly better SGRO Impacts and Total scores than the control group,
Table 2 Patient characteristics at baseline $(n=59)$

\begin{tabular}{|c|c|c|}
\hline & $\begin{array}{l}\text { Intervention } \\
(\mathrm{n}=31)\end{array}$ & $\begin{array}{l}\text { Control } \\
(\mathrm{n}=28)\end{array}$ \\
\hline \multicolumn{3}{|l|}{ Demographic data } \\
\hline Gender (M:F) & $16: 15$ & $14: 14$ \\
\hline Age (years) & $68.9(48-89)$ & $69.2(46-85)$ \\
\hline Weight (kg) & $54.5(7.3)$ & $53.5(8.5)$ \\
\hline Height (m) & $1.65(0.1)$ & $1.66(0.1)$ \\
\hline BMI $\left(\mathrm{kg} / \mathrm{m}^{2}\right)$ & $19.9(1.4)$ & $19.5(1.9)$ \\
\hline $\begin{array}{l}\text { Unintentional change from usual } \\
\text { weight }(\mathrm{kg})\end{array}$ & $-8.0(5.2)$ & $-9.2(6.2)$ \\
\hline$\%$ fat mass & $23.2(7.2) \dagger$ & $22.0(6.4)$ \\
\hline \multicolumn{3}{|l|}{ Smoking status } \\
\hline Ex-smokers & $18(58 \%)$ & $14(50 \%)$ \\
\hline Smokers & $11(36 \%)$ & $13(46 \%)$ \\
\hline Non-smokers & $2(6 \%)$ & $1(4 \%)$ \\
\hline \multicolumn{3}{|c|}{ Disease severity and respiratory function } \\
\hline $\mathrm{FEV}_{1}(\%$ predicted $)$ & $30.9(12.8)$ & $32.7(14.6)$ \\
\hline $\mathrm{FEV}_{1} / \mathrm{FVC}$ & $0.44(0.14)$ & $0.45(0.13)$ \\
\hline MRC dyspnoea score & $3(1-5)$ & $4(1-5)$ \\
\hline \multicolumn{3}{|l|}{ Social circumstances } \\
\hline $\begin{array}{l}\text { Lived with spouse/partner/family } \\
\text { members }\end{array}$ & $20(65 \%)$ & $18(64 \%)$ \\
\hline Lived alone & $11(35 \%)$ & $10(36 \%)$ \\
\hline \multicolumn{3}{|l|}{ Co-morbidities } \\
\hline Depression & $8(26 \%)$ & $10(36 \%)$ \\
\hline Hypertension & $11(35 \%)$ & $6(21 \%)$ \\
\hline Cardiovascular disease & $9(29 \%)$ & $7(25 \%)$ \\
\hline Gastro-oesophageal reflux & $3(10 \%)$ & $8(29 \%)$ \\
\hline \multicolumn{3}{|l|}{ Respiratory therapy } \\
\hline Oral steroids & $3(10 \%)$ & $1(4 \%)$ \\
\hline$\beta_{2}$-stimulants & $22(71 \%)$ & $19(68 \%)$ \\
\hline Bronchodilators & $19(51 \%)$ & $18(64 \%)$ \\
\hline Adrenostimulants & $10(32 \%)$ & $6(21 \%)$ \\
\hline Inhaled steroids & $23(74 \%)$ & $19(68 \%)$ \\
\hline Theophylline & $6(19 \%)$ & $5(18 \%)$ \\
\hline Long-term oxygen therapy & $7(23 \%)$ & $3(11 \%)$ \\
\hline \multicolumn{3}{|l|}{ Nutrient intake (diet history method) } \\
\hline Energy (kcal/day) & $1974(371)$ & $1931(425)$ \\
\hline Protein (g/day) & $68.5(11.6)$ & $66.1(11.6)$ \\
\hline \multicolumn{3}{|l|}{ Quality of life and functional status } \\
\hline SGRQ Total Score & $55.5(19.6)$ & $61.9(17.1)$ \\
\hline ADL score & $12(7-18)$ & $12(8-18)$ \\
\hline
\end{tabular}

Values are mean (SD) for weight, height, $\mathrm{BMI}$, unintentional weight change, \% fat mass, FEV ${ }_{1}(\%$ predicted), FEV $1 / F V C$, nutrient intake and SGRO Total Score; mean (range) for age; median (range) for MRC dyspnoea and ADL scores; number (\%) patients for smoking status, respiratory therapy, social circumstances and comorbidities.

$t \mathrm{n}=30$ as one patient did not consent to measurement.

$\mathrm{ADL}$, Activities of Daily Living; BMI, body mass index; $\mathrm{FEV}_{1}$, forced expiratory volume in $1 \mathrm{~s}$; FVC, forced vital capacity; SGRQ, MRC, Medical Research Council; St George's Respiratory Questionnaire.

although there was no difference in the Symptoms score. The difference in the Activity scores approached significance. In those who completed the study, improvements in SGRQ Impacts and Total scores continued after the cessation of nutritional intervention (table 4). The observed differences in scores were likely to be clinically significant since they exceeded the minimum clinically important difference of 4 points. ${ }^{21}$

The SF-36 Health Change score was significantly different in the intention-to-treat analysis and at both 6 and 12 months in those who completed the study, reflecting improvement in the intervention group and deterioration in the control group (table 4).

Perceived dyspnoea was less of a problem for the intervention group since the median dyspnoea score was significantly lower 

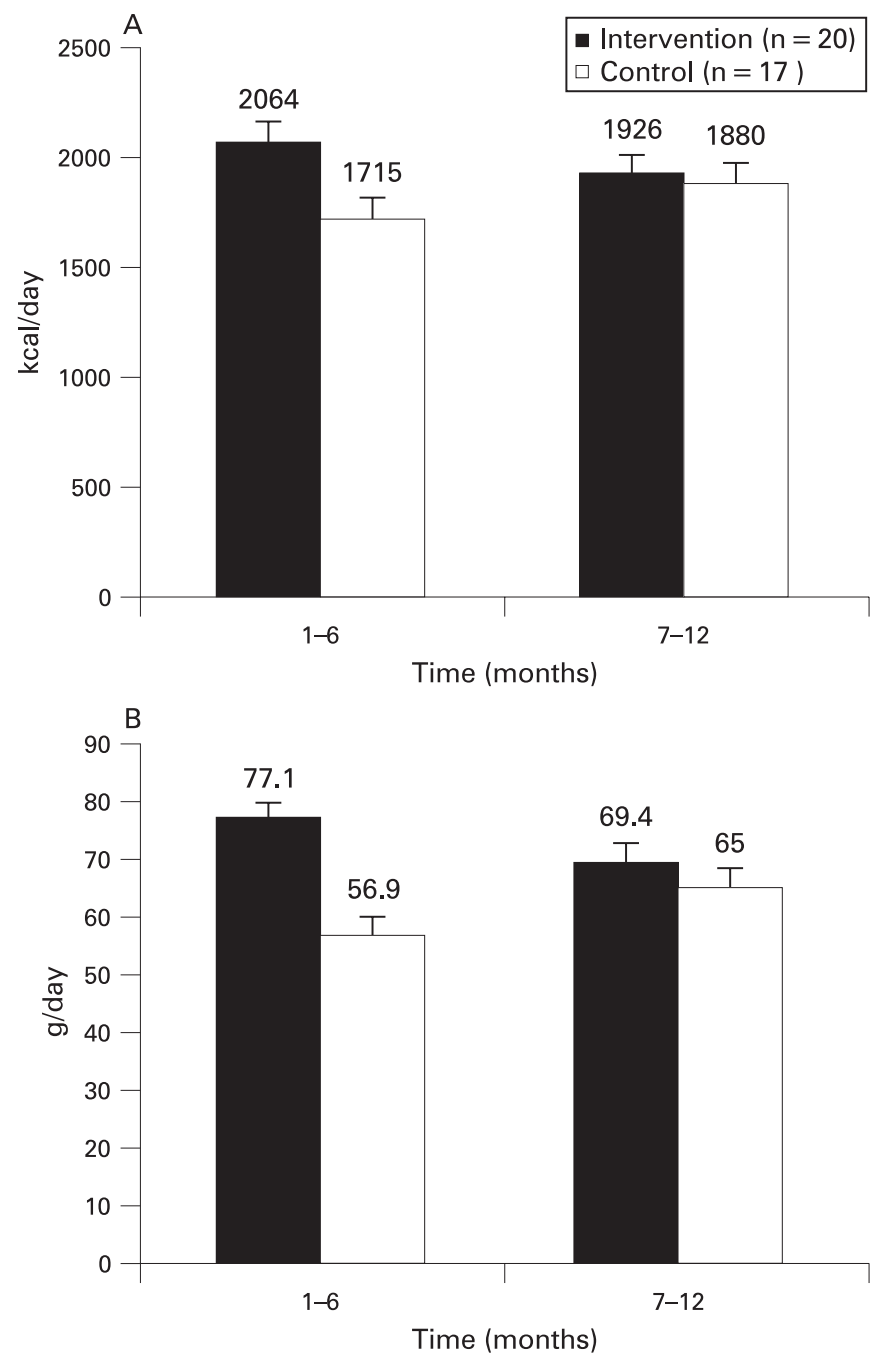

Figure 2 (A) Total energy and (B) total protein intake/day.

in the intervention group in the intention-to-treat analysis (intervention group: 3 (range 1-5); control group: 4 (range 1-5); $p=0.03)$. In those who completed the study, a significant difference was observed in dyspnoea scores at 6 months (intervention group: 3 (range 1-5); control group: 4 (range 2-5); $\mathrm{p}=0.002$ ) but not at 12 months (intervention group: 3 (range $1-5$ ); control group: 4 (range $2-5$ ); $p=0.24$ ). The observed differences in dyspnoea score were likely to be clinically significant, reflecting the difference between being able to walk less than 100 yards before being limited by dyspnoea and being able to walk further (eg, to the local shops).

The intervention group found it easier to perform everyday activities than the control group since the median ADL score in the intervention patients was lower than in controls. This approached statistical significance in the intention-to-treat analysis (intervention group: 11 (range 7-15); control group: 13 (range 9-18); $p=0.06$ ) and, in those who completed the study, the difference in scores between the groups was statistically significant at 6 months (intervention group: 11 (range 7-17); control group: 13 (range 8-18); $p=0.02$ ) and approached significance at 12 months (intervention group: 10 (range 7-16); control group: 13 (range 9-19); $p=0.06$ ).

In contrast to the subjective functional measures, no differences were observed between the groups in objective functional measures or respiratory function in either the

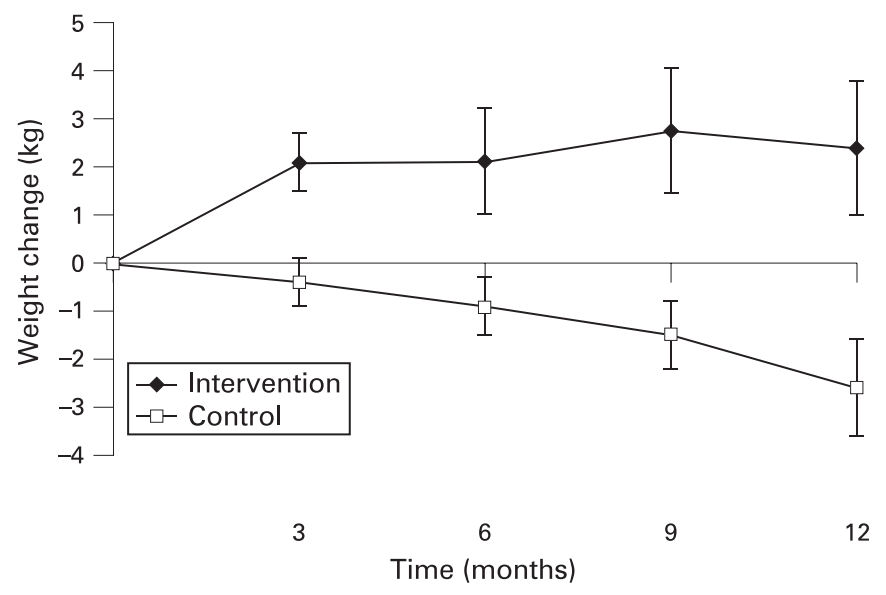

Figure 3 Weight change from baseline in patients who completed the study $(\mathrm{n}=37)$.

intention-to-treat analysis (table 3) or in those who completed the study (data not shown).

\section{DISCUSSION}

This is one of the first randomised controlled trials to evaluate the specific impact of dietary counselling on outcome in any patient group. ${ }^{4}$ The study is unusual in that it measured the effect of intervention not only on nutritional outcomes but also on objective and subjective measures of functional status. Furthermore, this study measured the effects of cessation of intervention, an area that is rarely investigated.

In the current study, dietary counselling resulted in significant benefits in dietary intake, body composition, quality of life and subjective measures of functional status. Intervention patients gained approximately $2 \mathrm{~kg}$ body weight during the intervention period and maintained weight during follow-up. This study therefore confirms the conclusions of a recent review that, in order to observe any benefits from nutritional intervention in outpatients with COPD, weight gain of at least $2 \mathrm{~kg}$ is required. ${ }^{3}$

Only two other studies have reported the effects of dietary counselling on body composition ${ }^{22}$ or patient-centred outcomes $^{23}$ in any patient group and, similar to the current study, the results showed that dietary counselling was beneficial. Possible reasons for these benefits include the fact that, in both studies, similar to the current study, counselling was individualised to each patient's needs and intervention lasted for at least 6 months. Similar to the current study, one of the studies found some beneficial effects persisted for at least 6 months beyond the intervention period. ${ }^{23}$ This persistence of the beneficial effects of dietary counselling beyond the intervention period contrasts with studies measuring the effects of cessation of ONS in general, ${ }^{3}$ and in outpatients with COPD in particular. ${ }^{24} 25$ In studies using ONS, cessation resulted in decreased nutritional intake and body weight towards baseline and some loss of functional benefits. Dietary counselling may result in changes in dietary habits which persist beyond the intervention period, a potential benefit of this strategy over the use of ONS. Furthermore, by tailoring advice to an individual's preferences, symptoms and lifestyle, it may be possible to achieve good compliance since using food and drink is likely to offer greater variety and flexibility than using ONS alone. In the current study, compliance was good with only four (14\%) intervention patients failing to comply with any advice or food fortification. No control patients made any significant 
Table 3 Energy and protein intake and measures of body composition, skeletal and respiratory muscle strength and respiratory function

\begin{tabular}{|c|c|c|c|c|c|}
\hline & Baseline & Intervention & Control & Difference $(95 \% \mathrm{CI})$ & p Value \\
\hline Dietary intake & & $(n=28)$ & $(n=22)$ & & \\
\hline Energy (kcal/day) & 1996 & $1979(54)$ & $1785(61)$ & 194 (31 to 357 ) & 0.02 \\
\hline Protein (g/day) & 67.8 & $72.7(1.8)$ & $60.9(2.0)$ & 11.8 (6.3 to 17.3$)$ & $<0.001$ \\
\hline Weight (kg) & 54.6 & $55.7(0.9)$ & $52.6(1.0)$ & $3.1(0.5$ to 5.7$)$ & 0.02 \\
\hline MAC (cm) & 25.9 & $26.2(0.3)$ & $25.3(0.4)$ & $0.9(0.0$ to 1.9$)$ & 0.05 \\
\hline MAMC $(\mathrm{cm})$ & 23.0 & $22.9(0.2)$ & $22.4(0.2)$ & $0.5(-0.2$ to 1.2$)$ & 0.13 \\
\hline Handgrip strength $(\mathrm{kg})$ & 23.0 & $22.2(0.4)$ & $21.9(0.5)$ & $0.3(-0.9$ to 1.6$)$ & 0.58 \\
\hline Pmax expiratory $\left(\mathrm{cm} \mathrm{H}_{2} \mathrm{O}\right)$ & 72.1 & $80.8(4.2)$ & $71.6(4.4)$ & $9.2(-2.9$ to 21.4$)$ & 0.13 \\
\hline Pmax inspiratory $\left(\mathrm{cm} \mathrm{H}_{2} \mathrm{O}\right)$ & 47.2 & $54.5(2.5)$ & $54.6(2.6)$ & $0.1(-7.4$ to 7.2$)$ & 0.98 \\
\hline Sniff pressure $\left(\mathrm{cm} \mathrm{H}_{2} \mathrm{O}\right)$ & 48.7 & $55.2(2.7)$ & $55.3(2.9)$ & $0.1(-8.1$ to 7.9$)$ & 0.98 \\
\hline $\mathrm{FEV}_{1}(\mathrm{I})$ & 0.83 & $0.78(0.03)$ & $0.81(0.04)$ & $0.03(-0.13$ to 0.07$)$ & 0.56 \\
\hline
\end{tabular}

Values are adjusted for baseline measurements and expressed as means (SE); difference: difference in measurements between intervention and control groups; $95 \%$ confidence interval (CI) for the difference between intervention and control groups; $\mathrm{p}$ values for ANCOVA tests between intervention and control groups. Intention-to-treat analysis.

${ }^{*} \mathrm{n}=29$ (one patient did not consent to measurement).

FEV 1 , forced expiratory volume in $1 \mathrm{~s}$; FVC, forced vital capacity; MAC, mid arm circumference; MAMC, mid arm muscle circumference; S4SF, sum of four skinfold thickness measurements.

improvements to their diet or bought MP, even though they received a leaflet recommending these strategies. More research is required comparing ONS with dietary counselling, including the specific effects of each strategy on dietary intake and behaviour, both during and after intervention. Since MP is not available on prescription, a cost analysis should be conducted and supply issues will need to be addressed if such products are to be used in routine clinical practice.
In the current study the intervention group showed improvements in psychosocial function, reflected in changes in quality of life scores. This may have beneficially influenced their motivation to undertake daily activities or their ability to cope with activityrelated dyspnoea. The mechanism for these effects has yet to be elucidated and further research is required in this area.

The observed differences between the groups in weight change, body composition, quality of life and subjective

Table 4 Quality of life

\begin{tabular}{|c|c|c|c|c|c|}
\hline & Baseline & Intervention & Control & Difference $(95 \% \mathrm{CI})$ & p Value \\
\hline \multicolumn{6}{|l|}{ SGRO } \\
\hline Intention-to-treat $(\mathrm{n}=41)$ & & $(n=23)$ & $(n=18)$ & & \\
\hline Activity & 73.4 & 70.4 & 78.7 & $8.3(-17.3$ to 0.5$)$ & 0.06 \\
\hline Symptoms & 60.6 & 59.5 & 61.6 & $2.1(-14.4$ to 10.3$)$ & 0.73 \\
\hline Total & 55.3 & 51.2 & 61.3 & $10.1(-18.5$ to -1.7$)$ & 0.02 \\
\hline \multicolumn{6}{|l|}{ Completed study $(n=37)$} \\
\hline Impacts & 46.1 & $42.3(2.8)$ & $48.5(3.0)$ & $6.2(-14.5$ to 2.2$)$ & 0.14 \\
\hline Symptoms & 62.8 & $63.2(2.4)$ & $66.6(2.5)$ & $3.4(-10.4$ to 3.7$)$ & 0.34 \\
\hline Total & 57.6 & $53.4(2.2)$ & $61.1(2.4)$ & $7.7(-14.4$ to -1.1$)$ & 0.02 \\
\hline \multicolumn{6}{|l|}{12 months } \\
\hline Activity & 75.4 & $69.3(2.9) \dagger$ & $80.5(3.0)$ & $11.2(-19.8$ to -2.7$)$ & 0.01 \\
\hline \multicolumn{6}{|l|}{ Short Form-36 } \\
\hline Intention-to-treat $(\mathrm{n}=41)$ & & $(n=23)$ & $(n=18)$ & & \\
\hline Health change & 34.8 & $51.7(5.6)$ & $32.5(6.4)$ & $19.2(2.0$ to 36.4$)$ & 0.029 \\
\hline \multicolumn{6}{|l|}{ Completed study ( $\mathrm{n}=37)$} \\
\hline 6 months & & $(n=19) \S$ & $(n=17)$ & & \\
\hline Health change & 35.4 & $53.8(4.8)$ & $29.6(5.0)$ & $24.2(10.1$ to 38.3$)$ & 0.001 \\
\hline 12 months & & $(n=18)$ & $(n=16)$ & & \\
\hline Health change & 33.8 & $55.2(5.7)$ & $28.5(6.1)$ & 26.7 (9.7 to 43.7$)$ & 0.003 \\
\hline
\end{tabular}


functional measures in this study occurred in the absence of changes in objective functional measures. These results concur with those reported in a recent review ${ }^{2}$ where nutritional support had no significant effect on lung function or respiratory muscle strength in patients with stable COPD. The majority of patients in the current study were sedentary and more than one-quarter were effectively housebound. The role of nutritional intervention (dietary counselling and/or ONS) in conjunction with pulmonary rehabilitation and/or exercise training therefore requires evaluation.

There are a number of limitations to this study, a major one being the potential for bias arising from inadequate blinding to treatment allocation and outcome assessment. To minimise bias, all results were analysed at the end of the study and no interim analyses were conducted. Furthermore, the dietary diaries were analysed by two independent dieticians, both of whom were blind to the treatment group and outcome assessment. Future studies evaluating the impact of dietary counselling and food fortification should be adequately blinded to determine if the observed treatment effect in the current study can be replicated.

The observed differences between the groups in weight change are not fully accounted for by the differences in recorded dietary intake, particularly in the 6 months following cessation of intervention. Two different methods were used to assess intake (ie, the diet history method at baseline and 5-day dietary diaries at all subsequent assessments). Results from the two methods are not directly comparable since diet history tends to overestimate intake and, due to under-reporting, dietary diaries tend to underestimate. ${ }^{12}$ While changes in dietary behaviour may account for some of the observed differences in weight change and dietary intake in the current study, other factors may have contributed, in particular differences in physical activity level, energy expenditure or inflammatory status. Since data on physical activity and energy expenditure were not collected in the current study, it is not possible to determine the relative contributions of these potential confounding factors. Some patients with COPD exhibit a low-level inflammatory response, ${ }^{26}{ }^{27}$ the consequences of which may result in a poor response to nutritional intervention. ${ }^{26}$ Inflammatory markers were not measured in the current study so it is not possible to determine whether any patients who failed to respond to dietary counselling had a low-level inflammatory response.

The control group received a leaflet encouraging food fortification and providing advice for increasing nutritional intake. In clinical practice, this may be the extent of nutritional intervention for outpatients with COPD and this study suggests that, compared with dietary counselling and advice on food fortification, it is ineffective in achieving weight gain and functional benefits in this patient group. Further studies are required to establish which patients are most likely to respond to-and potentially benefit from-dietary counselling and advice on food fortification. The possible effects of inflammatory status, psychosocial function, coping strategies, exercise training and pulmonary rehabilitation also require evaluation.

\footnotetext{
Acknowledgements: The authors thank the consultant respiratory physicians, in particular Dr Nigel Bateman, at Guy's, St Thomas' and Lewisham Hospitals for access to their patients during the conduct of this study; Professor Sue Chinn (Department of Public Health Medicine, King's College, London) and Mr Peter Milligan (School of Biomedical and Health Sciences, King's College, London) for statistical advice; and Mrs Hilary McGeogh (Dietetic Manager, Wellington Hospital, London) and Ms Christina Pateras (Student Dietitian, King's College, London) for analysing and reviewing the dietary diaries.
}

Funding: During the conduct of this study CEW received Research Training Fellowship awards from the London Regional NHS Executive and the Guy's and St Thomas' Hospital Charitable Foundation.

Competing interests: None.

Ethics approval: Ethical approval was obtained from the Guy's and St Thomas' Hospital NHS Trust ethics committee (EC97/363) and the University Hospital Lewisham ethics committee (03/08/12)

\section{REFERENCES}

1. Landbo $\mathbf{C}$, Prescott $E$, Lange $P$, et al. Prognostic value of nutritional status in chronic obstructive pulmonary disease. Am J Respir Crit Care Med 1999;160:1856-61.

2. Ferreira IM, Brooks D, Lacasse $Y$, et al. Nutritional supplementation for stable chronic obstructive pulmonary disease (Cochrane Review). Cochrane Database System Rev 2000

3. Stratton RJ, Green CJ, Elia M. Disease-related malnutrition: an evidence-based approach to treatment. Wallingford, Oxon: CAB International, 2003.

4. Baldwin C, Parsons T, Logan S. Dietary advice for illness-related malnutrition in adults. Cochrane Database System Rev 2001;(2):1-67.

5. Payette H, Boutier V, Coulombe C, et al. Benefits of nutritional supplementation in free-living, frail, undernourished elderly people: a prospective randomized community trial. J Am Dietetic Assoc 2002;102:1088-95.

6. Bonnefoy M, Cornu C, Normand S, et al. The effects of exercise and protein-energy supplements on body composition and muscle function in frail elderly individuals: a long-term controlled randomised study. Br J Nutr 2003;89:731-8.

7. Bolton J, Shannon V, Smith V, et al. Comparison of short-term and long-term palatability of six commercially available oral supplements. J Human Nutr Dietetics 1990; 3:317-21

8. Keele AM, Bray MJ, Emery PW, et al. Two phase randomised controlled clinical trial of postoperative oral dietary supplements in surgical patients. Gut 1997;40:393-9.

9. Lad H, Gott M, Gariballa SE. Health professionals' and elderly patients' views, attitudes and compliance with prescribed oral nutritional supplements. Proc Nutr Soc 2004;63:43A.

10. Weekes CE, Elia M, Emery PW. The development, validation and reliability of a nutrition screening tool based on the recommendations of the British Association for Parenteral and Enteral Nutrition (BAPEN). Clin Nutr 2004;23:1104-12.

11. National Advisory Group for Elderly People. Have you got a small appetite? Birmingham: British Dietetic Association, 2001.

12. Bingham SA. The dietary assessment of individuals; methods, accuracy, new techniques and recommendations. Nutr Abstr Rev (Series A) 1987;57:705-42.

13. Durnin JVGA, Womersley J. Body fat assessed from total body density and its estimation from skinfold thickness: measurements on 481 men and women aged from 16 to 72 years. Br J Nutr 1974;32:77-97.

14. Jones PW, Quirk FH, Baveystock CM, et al. A self-complete measure of health status for chronic airflow limitation. The St George's Respiratory Questionnaire. Am Rev Respir Dis 1992;145:1321-7.

15. Ware JE, Sherbourne CD. The MOS 36-Item Short-Form Health Survey (SF-36) I: conceptual framework and item selection. Med Care 1992;30:473-83.

16. Medical Research Council. Questionnaire on respiratory symptoms: instructions to interviewers. London: MRC Committee on Environmental and Occupational Health, 1986

17. Bond J, Carstairs V. Services for the elderly: a survey of the characteristics and needs of a population of 5,000,000 old people. Edinburgh: Scottish Home and Health Department, 1982:42.

18. Griffith CDM, Clark RG. A comparison of the "Sheffield" prognostic index with forearm muscle dynamometry in patients from Sheffield undergoing major abdominal and urological surgery. Clin Nutr 1984;3:147-51.

19. Kolouris N, Mulvey DA, Laroche CM, et al. The measurement of inspiratory muscle strength by sniff esophageal, nasopharyngeal and mouth pressures. Am Rev Respir Dis 1989;139:641-6.

20. Vickers AJ, Altman DG. Analysing controlled trials with baseline and follow up measurements. BMJ 2001;323:1123-4.

21. Jones PW. Interpreting thresholds for a clinically significant change in health status in asthma and COPD. Eur Respir J 2002;19:398-404.

22. Campbell KL, Ash S, Davies PSW, et al. Randomised controlled trial of nutritional counselling on body composition and dietary intake in severe CKD. Am J Kidney Dis 2008; $51: 748-58$

23. Imes S, Pinchbeck B, Thomson ABR. Diet counselling improves the clinical course of patients with Crohn's disease. Digestion 1988;39:7-19.

24. Efthimiou J, Fleming J, Gomes C, et al. The effect of supplementary oral nutrition in poorly nourished patients with chronic obstructive pulmonary disease. Am Rev Respir Dis 1988;137:1075-82.

25. Knowles JB, Fairbarn MS, Wiggs BJ, et al. Dietary supplementation and respiratory muscle performance in patients with COPD. Chest 1988;93:977-83

26. Creutzberg EC, Schols AMWJ, Weling-Scheepers CAPM, et al. Characterization of non-response to high caloric oral nutritional therapy in depleted patients with chronic obstructive pulmonary disease. Am J Respir Crit Care Med 2000;161:745-52.

27. Eid AA, lonescu AA, Nixon LS, et al. Inflammatory response and body composition in chronic obstructive pulmonary disease. Am J Respir Crit Care Med 2001;164:1414-8. 